\title{
Construções metafóricas espaciais literárias e do cotidiano em narrativas míticas indígenas
}

\author{
Literary and daily spatial metaphorical constructions in indige- \\ nous mythic narratives \\ Joeliza Lamarão Bezerra \\ Wany Bernardete de Araujo Sampaio ${ }^{1}$
}

\begin{abstract}
Resumo
Este trabalho apresenta resultados parciais do projeto de pesquisa $A$ metáfora literária e do cotidiano em narrativas míticas indígenas. A pesquisa se fundamenta na Teoria Cognitiva da Metáfora (Lakoff \& Johnson 2002) segundo a qual o elemento metafórico permeia todas as nossas ações e pensamento, além da linguagem, pois está infiltrado no nosso cotidiano; existe uma extensão contínua entre as metáforas literárias e as metáforas cotidianas; as ocorrências da metáfora nas obras literárias acontecem não exclusivamente porque a literatura contém a linguagem cotidiana, mas porque mesmo que haja um desvio das formas mais comuns (cotidianas) de expressão e de pensamento, a linguagem é realizada a partir de explorações criativas e inusitadas de mapeamentos metafóricos enraizados em nossos sistemas conceptuais. Como foco da análise, são tomadas expressões que envolvem imagens metafóricas do espaço; a partir do conceito de Metáforas Orientacionais, referentes a orientação espacial do tipo: para cima-para baixo, dentro-fora, frente-trás, em cima de, fora de, fundo-raso, central-periférico. Desse modo, a presente pesquisa apresenta a análise de construções metafóricas que evidenciam o domínio do espaço contidas em narrativas indígenas de cunho mítico; tais narrativas são de autoria indígena e escritas em língua portuguesa por narradores e professores indígenas. A partir da análise das metáforas de cunho conceitual, realiza-se uma discussão sobre as metáforas de caráter literário na literatura escrita indígena.
\end{abstract}

Palavras-chave: Metáfora. Espaço. Mito. Literatura.

\begin{abstract}
This paper presents partial results of the research project The literary and everyday metaphor in indigenous mythical narratives. The research is based on Cognitive Theory of Metaphor (Lakoff \& Johnson 2002) according to which the metaphorical element pervades all our actions and thinking, beyond language, as it is infiltrated in our daily lives; there is a continuous extension of the literary metaphors and everyday metaphors; the metaphor of events in literary works take place not only because literature contains everyday language, but because even if there is a deviation of the most common forms (daily) of expression
\end{abstract}

\footnotetext{
${ }^{1}$ Doutora em Linguística; Doutora em Educação Escolar; Pós-Doutora em Linguística Cognitiva. Grupo de Estudos em Culturas, Educação e Linguagens - GECEL/UNIR/CNPq. Fundação Universidade Federal de Rondônia - UNIR.wansamp@gmail.com
} 
and thought, language is made from creative explorations and unusual of metaphorical mappings rooted in our conceptual systems. The analysis focuses expressions involving metaphorical space images; from the concept of orientational metaphors, which refers to spatial orientation of the type: up-down, inside-out, front-back, on, off, deep-shallow, central-peripheral. Thus, this research presents the analysis of metaphorical constructions which show the space-domain contained in indigenous narratives of mythical nature; such narratives are written in Portuguese by narrators and indigenous teachers. From the analysis of conceptual nature metaphors, we discuss about the literary character of metaphors in writing indigenous literature.

Keywords: Metaphor. Space. Myth. Literature.

\section{Introdução}

Guesse (2011) afirma que somente nas duas últimas décadas a matéria estética dos textos narrativos indígenas passou a ser considerada pelos estudos literários, revelando que as manifestações literárias indígenas foram, ao longo do tempo, objeto de estudos antropológicos, mas não de estudos literários. O material escrito indígena encontra-se, em sua variedade, tanto em sua língua de origem quanto em língua portuguesa. Existem também produções apenas na língua indígena, outras apenas em língua portuguesa, há disponíveis narrativas em língua indígena com tradução para o português e materiais que apresentam as duas versões (e não traduções) das histórias, uma em língua indígena e outra em língua portuguesa. A autora conclui que estudos voltados à literatura indígena e sua ligação com as teorias literárias "oficiais" ainda são pouco explorados no meio acadêmico, pois existe, por parte da crítica literária, uma resistência em relação às produções culturais indígenas. Souza (2003) afirma que a literatura indígena, em especial a produzida em língua portuguesa, já nasce marginal, pois ainda não mereceu o interesse das academias que a classificam como literatura popular ou de massas, sem grande valor literário.

Buscando contribuir para o campo dos estudos literários dos textos narrativos indígenas, o presente trabalho apresenta a análise de construções linguísticas metafóricas de cunho conceitual a partir da Teoria Cognitiva da Metáfora (Lakoff e Johnson 2002). Lakoff e Johnson (2002) afirmam que a metáfora está infiltrada na vida cotidiana e que não constituem meras questões do intelecto. Afirmam, ainda, que as metáforas literárias são extensões, combinações ou elaborações de projeções metafóricas mais básicas e estão presentes nos textos literários não porque a literatura agrega a linguagem do cotidiano, mas porque, mesmo quando há intenção de promover o desvio das formas cotidianas de expressão e pensamento, isto é feito a partir de explorações criativas e inusitadas de construções metafóricas incorporadas em nossos sistemas conceptuais.

A análise deste trabalho consiste, em parte, da discussão desenvolvida no projeto A metáfora literária e do cotidiano em narrativas míticas indígenas, 
em desenvolvimento pela primeira autora junto ao programa de Mestrado em Estudos Literários/UNIR, com apoio da CAPES e CNPq, sob a orientação da Profa. Dra. Wany B. A. Sampaio. Com base em estudos disponíveis na área de linguística cognitiva e também dos estudos literários, pretende-se discutir fatores literários da narrativa a partir da análise das metáforas conceptuais presentes em narrativas míticas indígenas, escritas em língua portuguesa; pretende-se, ainda, refletir sobre a atitude literária do narrador indígena, privilegiando o papel e a voz do narrador, a fim de valorizar os estudos estético-literários de narrativas indígenas.

As narrativas analisadas pertencem ao acervo do Grupo de Estudos em Culturas, Educação e Linguagens - GECEL/UNIR/CNPq. As narrativas foram escritas em língua portuguesa por professores indígenas que frequentaram o Projeto Açaí, um curso de formação de professores indígenas promovido pela Secretaria de Estado da Educação do Estado de Rondônia. Os textos foram produzidos na disciplina de Estágio Supervisionado, ministrada pelas professoras Ms. Maria de Fátima Molina e Dra. Wany Bernadete de Araujo Sampaio, no ano de 2011.

O foco da presente análise consiste no estudo de uma construção metafórica em que se evidencia a noção de espaço e movimento no âmbito das Metáforas Orientacionais e as Metáforas Ontológicas do tipo espacial, segundo a Teoria Cognitiva da Metáfora.

O texto aqui apresentado está organizado em duas partes: na primeira, é realizado um breve levantamento bibliográfico acerca da metáfora de cunho conceitual sob a perspectiva da Teoria Cognitiva da Metáfora; na segunda, tem-se a apresentação de uma narrativa em que será descrita e analisada uma ocorrência de construção metafórica de cunho conceitual, bem como a discussão acerca da metáfora literária.

\section{A teoria cognitiva da metáfora}

Conforme postula Cassirer (1992), o homem, com a intenção de atender as necessidades sempre crescentes do seu espírito, foi obrigado a falar e expressarse de maneira metafórica; no entanto, este falar metafórico não é compreendido apenas como uma questão de poética, desvio ou ornamento, mas sim como uma forma de atender as suas necessidades primeiras. Por definição, Cassirer (1992:104) afirma que:

Pode-se tomar este conceito no sentido em que seu domínio abrange tão somente a substituição consciente da denotação por um conteúdo de representação, mediante o nome de outro conteúdo que se assemelhe ao primeiro em algum traço, ou tenha com ele qualquer "analogia" indireta.

O ponto de partida para a discussão da metáfora de cunho literário é a metáfora de base conceitual. Por esse motivo, com base na linguística cognitiva, 
priorizando como se dá a apreensão do mundo e dos seres do mundo, considerase tão relevante o estudo através da metáfora e seu funcionamento na linguagem, língua e conhecimento. Lakoff e Johnson (2002) postulam que as metáforas, chamadas por ele de conceitos metafóricos, regem nosso pensamento e também as atividades mais comuns que realizamos em nosso cotidiano; por isso tais sistemas conceituais são responsáveis por estruturar e definir a realidade cotidiana na qual estamos inseridos. Desse modo, toda a nossa experiência é totalmente cultural, pois experienciamos o mundo de tal maneira que nossa cultura já está presente na experiência em si (Lakoff e Johnson, 2002:129). Os fatores culturais são expressos pela língua; portanto eles devem ser considerados nos estudos linguísticos e literários. Por essa razão, as metáforas conceituais desempenham um papel crucial na conceituação de muitos termos (domínios), uma vez que constituem uma maneira de pensar também em domínios como, por exemplo, a Literatura. De acordo com Lakoff e Johnson (2002):

Os conceitos que governam nosso pensamento não são meras questões de intelecto: Eles governam também a nossa atividade cotidiana até nos detalhes mais triviais. Eles estruturam o que percebemos, a maneira como nos comportamos no mundo e o modo como nos relacionamos com outras pessoas. Tal sistema conceitual desempenha, portanto, um papel central na definição de nossa realidade cotidiana (Lakoff e Johnson 2002:45).

Dentre as discussões que norteiam nossa pesquisa, consideramos primordial a reflexão acerca do objeto da investigação literária. Wellek e Warren (1976), ao tratar da natureza da literatura, se deparam com a mesma problemática: qual o objeto da investigação literária?

O meio encontrado pelos autores, a fim de buscar a resposta para qual o objeto da investigação literária, consiste em por em evidência o modo particular de utilização da linguagem na literatura. Para Wellek e Warren (1976), é a linguagem o material da literatura. Os estudiosos afirmam que "a linguagem científica ideal é puramente denotativa: visa uma correspondência de um para um entre o signo e a coisa significada" e sobre a linguagem literária, posta em comparação à científica "é uma linguagem altamente conotativa" (Wellek; Warren 1976:24).

Ao realizar a distinção entre a linguagem científica e a linguagem literária, Wellek e Warren (1976) também avaliam a dificuldade em fazer tal distinção entre a linguagem literária e a linguagem diária. Tal dificuldade se configura no que diz respeito originalmente ao conceito de linguagem diária. A linguagem diária, conforme dizem os autores:

(...) não é uniforme: inclui largas variedades, como a linguagem coloquial, a linguagem do comércio, a linguagem oficial, a linguagem da religião, o calão dos estudantes. (...) Assim, a linguagem de todos 
os dias também tem a sua função expressiva, embora esta possa variar - desde uma incolor comunicação oficial até a uma apaixonada veemência suscitada por um momento de crise emocional. (Wellek; Warren 1976:25).

Conforme Cassirer (1992), a compreensão da metáfora não se dá apenas como uma determinada tendência da linguagem, mas como uma condição constitutiva dela e por isso esclarece a correlação entre linguagem e mito; segundo o autor,

(...) a linguagem e o mito se acham originariamente em correlação indissolúvel, da qual só aos poucos cada um vai se desprendendo como membro independente. Ambos são ramos diversos do mesmo impulso de informação simbólica, que brota de um mesmo ato fundamental de elaboração espiritual, da concentração e elevação da simples percepção sensorial. Nos fonemas da linguagem, assim como nas primitivas configurações míticas, consuma-se o mesmo processo interior; ambos constituem a resolução de uma tensão interna, a representação de moções e comoções anímicas em determinadas formações e conformações objetivas. (Cassirer 1992:106)

Benveniste (1995) apud Ricoeur (2000) postula que as palavras não têm um sentido próprio, mas sim que seu sentido é produzido no discurso e pelo discurso. A linguagem é colocada como metafórica e a metáfora não é uma forma de desvio, mas sim uma parte que constitui a linguagem. Tal premissa leva-nos a conceber a metáfora seguindo um caminho que sai da classificação e é colocada na significação, ou seja, sai da referência e é posta na transcendência. A existência da metáfora ao nível da frase (Ricoeur 2000) é configurada como interpretação em que há uma desconstrução de um sentido literal e o surgimento de uma palavra com um sentido novo, interpretativo.

De acordo com a Teoria Cognitiva da Metáfora, o processo que se refere ao nosso sistema conceitual não ocorre de maneira consciente, uma vez que, durante grande parte de nossas atividades cotidianas, fazemos e pensamos de maneira quase automática. Por isso, Lakoff e Johnson (2002) consideram que uma das formas de investigação das metáforas é através da linguagem e justificam que a comunicação tem por base o nosso sistema conceitual e que o utilizamos a fim de pensar e agir, desse modo é na linguagem que se encontra a maior fonte de evidências de como se realiza esse processo conceitual.

Lakoff e Johnson (2002) apresentam alguns tipos de metáforas como: orientacionais, ontológicas e estruturais, usadas comumente para as ideias conceituais. Neste trabalho, daremos enfoque às metáforas orientacionais e ontológicas do tipo orientacional. 


\subsection{Metáforas orientacionais}

Conforme os estudos de Lakoff e Johnson (2002) as metáforas do tipo orientacional não somente estruturam um conceito em termos de outro, mas têm a capacidade de organizar um sistema global de conceitos em relação ao outro. Grande parte das construções metafóricas tem relação com a orientação espacial: para cima-para baixo, dentro-fora, frente-trás, profundo-superficial, central-periférico. Como exemplo, podemos fazer a relação FELIZ com a noção espacial PARA CIMA e TRISTE com a noção espacial PARA BAIXO. Segundo os autores, estas metáforas surgem a partir do fato de termos um determinado tipo de corpo interagindo em um espaço físico específico.

Dessa forma, temos tais orientações baseadas em nossa experiência física e cultural, ou seja, mesmo que tais orientações sejam de natureza física, as metáforas orientacionais podem apresentar variações de uma cultura para outra. Há, portanto, um sistema de coerência interna nas construções. Além disso, os estudos das metáforas orientacionais comprovam que tais metáforas estão na base de nosso sistema conceitual, permitindo-nos entender o mundo, bem como dar valor aos conceitos por nós criados. Isso ocorre, segundo os autores, porque as metáforas orientacionais estão ligadas aos valores culturais, por isso encontramos exemplos em que a noção espacial "para cima" é considerada, como algo positivo, bom e a noção espacial "para baixo" é tida como algo negativo, ruim.

\subsection{Metáfora ontológica}

Lakoff e Johnson (2002), ao tratar das metáforas ontológicas, afirmam que o ser humano apresenta uma limitação de superfície, por isso nossa compreensão acerca de nós mesmos é o que nos permite impor limites artificiais onde não existam contornos definidos. Desse modo, é a partir da compreensão dada a certas experiências em caráter de objetos ou substâncias que nos proporcionam fazer referências a elas, categorizá-las, agrupá-las, quantificá-las e raciocinar sobre as experiências. Logo, podemos conceber atividades, emoções e eventos em termos de entidades e substâncias. Conforme os autores, as metáforas ontológicas nos permitem lidar racionalmente com nossas experiências. Seguem afirmando que somos seres de constituição física, limitados e separados do resto do mundo pela superfície de nossa pele e por isso experenciamos o mundo externo, como o "lado de fora". Nós, seres humanos, apresentamo-nos, então, como um recipiente e através da experiência corpórea somos capazes de perceber a noção de estarmos dentro ou fora de algum lugar.

Vale ressaltar que a Teoria Cognitiva da Metáfora considera a natureza da metáfora conceitual e não linguística, portanto as expressões criadas a partir de tais conceitos é que são linguísticas; por isso a ideia do corpo enquanto recipiente e sua interação com o mundo irá se apresentar na linguagem. 


\section{Análise da narrativa}

A fim de realizar a análise das construções metafóricas, foram analisadas narrativas escritas em língua portuguesa por indígenas de várias etnias no curso de formação de professores indígenas; os textos escritos foram produzidos em grupos, após uma discussão coletiva com o tema "Saberes Indígenas". Dentre as narrativas, selecionamos uma, a seguir transcrita, para ilustrar nossa análise.

\section{Aldeia Palhal}

Eu moro na aldeia palhal vou contar um pouco da historia do povos Tupari que ainda preserva a sua cultura. Quando o casal tem filho tem cumprir o resguardo do filho recém-nascido, é obrigado os pai fazer esse resguardo do filho, logo que a criança nasce, no outro dia, o pajé é convidado pela família para fazer o ritual. Então o pajé chega e senta no banquinho e pede para a mãe com a criança, no colo e o pai, do lado sentarem na frente do pajé para receber o ritual, o pajé também vai fazer a cura dos alimento, porque tem vários alimento que os pai não podem comer por causa da criança. Se o pai ou a mãe comer certo alimento vai prejudicar a saúde do seu bebê. E por isso que a cultura do povo Tupari ainda mantem essa tradição e dai pai ou a mãe que comer alimento antes do tempo os mais velhos o avô ou avó até mesmo o pajé podem ir no mato atrás de raizes para fazer sumo da raiz para os pais beberem. O remédio tradicional e muito importante para os indígenas, tomando essas raizes e também tomando banho de folhas os indiozinhos crescem saudável e forte.

Autores: Arlene Tupari, Edna Aruá, Misma Canoé, Valmir Makurap, Mauricio Tupari.

Da narrativa transcrita, destacamos a seguinte construção metafórica orientacional:

(1) Então o pajé chega e senta no banquinho e pede para a mãe com a criança, no colo e o pai, do lado sentarem na frente do pajé para receber o ritual.

Observa-se nesta construção (1) a imagem metafórica RITUAL É UMA SUBSTÂNCIA FÍSICA, através da qual é possível conceituar o abstrato com base no concreto, a partir da experiência com objetos ou substâncias físicas, permitindo-nos conceber um evento como substância material.

Assim, tomando o aspecto experiencial da metáfora, a compreensão da imagem metafórica RITUAL É UMA SUBSTÂNCIA FÍSICA conceitualiza o corpo como um RECIPIENTE, ou seja, o corpo humano é um CONTENTOR. Tal conceito se dá em decorrência de que o nosso contato com a realidade cotidiana nos revela o corpo como um depósito onde recebemos/depositamos comida, bebida e também expelimos para o exterior outras substâncias que 
não nos servem. O esquema imagético de contentor é imprescindível para esta análise, uma vez que a conceitualização de RITUAL como uma substância física reflete a noção dentro-fora com relação ao corpo humano.

A construção metafórica (1) possibilita também a conceitualização do RITUAL enquanto trajetor, pois o evento reflete a progressão dentro de um espaço em que o ritual é direcionado para frente. Temos na construção a descrição da posição dos corpos humanos no espaço: o pajé sentado no banquinho, a mãe com a criança no colo e o pai do lado, sentados na frente do pajé.

(1) Então o pajé chega e senta no banquinho e pede para a mãe com a criança, no colo e o pai, do lado sentarem na frente do pajé para receber o ritual.

Segundo Almeida (2001), os esquemas imagéticos pré-conceptuais são fundamentais para a compreensão dos conceitos de relação espacial e de movimento. Sendo assim, consideramos importante utilizar como suporte para a análise dos dados o esquema imagético do contentor e o esquema imagético da trajetória, visto que:

(...) esquemas imagéticos são noções conceituais fundamentais, padrões dinâmicos que funcionam como uma estrutura abstrata de uma imagem, e que, consequentemente ligam um leque vasto de diferentes experiências dotadas da mesma estrutura recorrente. (Almeida 2001:62).

Portanto, temos por esquemas imagéticos:

a) Esquema imagético do CONTENTOR

Então o pajé chega e senta no banquinho e pede para a mãe com a criança, no colo e o pai, do lado sentarem na frente do pajé para receber o ritual.

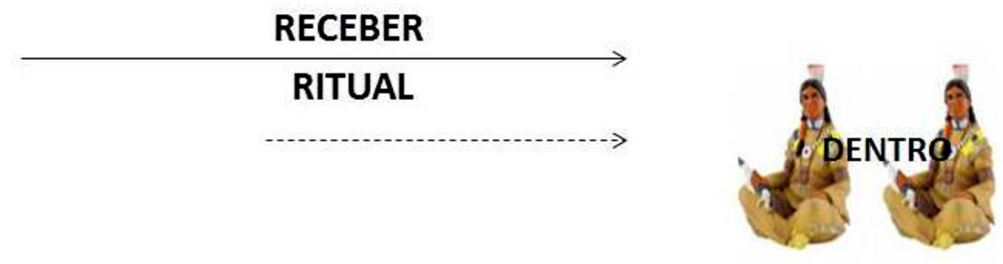

(FORA)

- Imagem metafórica: RITUAL É UMA SUBSTÂNCIA FÍSICA

- O Corpo é um RECIPIENTE

- O Corpo é um CONTENTOR 
$\mathrm{Na}$ construção linguística metafórica ocorre a seleção da palavra receber, reforçando a ideia do ritual como uma substância física, material, pois significados referentes ao verbo receber são: aceitar algo que lhe é oferecido ou dado, ganhar, adquirir e herdar.

Compreendemos que, através da escolha do verbo receber, seja possível perceber a intencionalidade do narrador/escritor ao produzir o texto, pois, ao estruturar a narrativa, o narrador faz as relações com a palavra escolhida a partir do seu léxico e de sua intenção. A utilização do verbo é capaz de esclarecer e transmitir o sentimento da ação. A partir da construção linguística metafórica é possível concretizar uma experiência abstrata e de valor social. Podemos pensar o ritual, substância física, como uma espécie de "presente" na cultura indígena, pois a escolha do verbo receber (aceitar algo que é dado) nos permite isso como interpretação.

Mito e ritual são termos correlativos, pois o mito é a parte falada do ritual ou, como postulam Wellek e Warren (1976), o mito é a história do ritual. Na narrativa analisada, confirma-se o que os teóricos tratam acerca do ritual, uma vez que é executado para uma determinada sociedade (indígenas - a mãe, a criança e o pai) pelo seu representante (o pajé) cujo objetivo é evitar ou propiciar qualquer coisa (para a criança crescer forte e saudável).

b) Esquema imagético do CONTENTOR

Então o pajé chega e senta no banquinho e pede para a mãe com a criança, no colo e o pai, do lado sentarem na frente do pajé para receber o ritual.

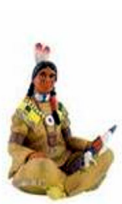

ORIGEM

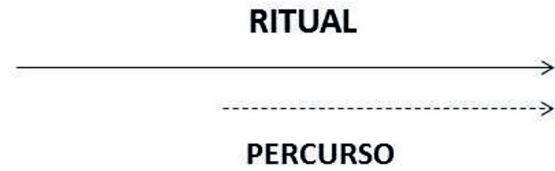

PERCURSO

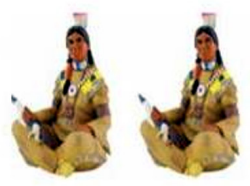

ALVO

- Imagem metafórica: RITUAL É UMA SUBSTÂNCIA FÍSICA QUE SE MOVE

\section{- O Ritual é um TRAJETOR}

A análise propõe o esquema imagético pré-conceitual do CONTENTOR (em que está subjacente os conceitos de DENTRO e FORA) - e o esquema da TRAJETÓRIA em que as imagens remetem, necessariamente, para alteração 
da posição dos elementos no espaço da ORIGEM (focagem do ponto de partida) para o ALVO (focagem do ponto-final) e, da separação entre esses dois pontos, temos o PERCURSO.

Desse modo, as construções analisadas apontam que o modo como falamos e pensamos possui uma base metafórica e é a nossa interação com o mundo que nos fornece a base conceitual para elaborarmos construções linguísticas metafóricas.

\subsection{Metáforas na literatura escrita indígena}

Segundo Guesse (2011), a língua do branco, antes usada como uma maneira de dominar e manipular os saberes, ao passar para o indígena no domínio da escrita, este a utiliza como um meio de expressão comunicativa e criativa, bem como um modo de promover a valorização de seus costumes e em especial a manutenção de sua identidade cultural.

Araújo (2010) diz que "Os povos indígenas, ao contarem suas histórias, escrevem, pois percebem na permanência da palavra escrita o lugar da memória". Sobre o papel da literatura indígena, Daniel Munduruku afirma que:

A escrita é a demonstração de capacidade de transformar a memória em identidade, pois ela reafirma o Ser na medida em que precisa adentrar no universo mítico para dar-se a conhecer ao outro. O papel da literatura indígena é, portanto, ser portadora da boa notícia do (re) encontro. Ela não destrói a memória na medida em que a reforça e acrescenta ao repertório tradicional outros acontecimentos e fatos que atualizam o pensar ancestral. (Munduruku 2008)

Segundo Benjamin (1987) a arte de narrar consiste na possibilidade de trocar experiências e esta, de algum modo, está desprovida do homem. Benjamin insere o narrador na categoria entre os mestres e os sábios, pois o narrador sabe dar conselhos. O narrador usa a sua experiência e a do próximo para constituir sua base. Para Benjamin, "seu dom é poder contar sua vida; sua dignidade é contá-la inteira. (...) O narrador é a figura na qual o justo se encontra consigo mesmo" (Benjamin 1987: 221).

E como é possível identificar a atitude literária no narrador em uma produção escrita indígena? É a partir dos estudos e análises do presente trabalho, com base nos conceitos extraídos da linguística cognitiva e também dos estudos literários, que faremos reflexão e discussão acerca da metáfora de cunho literário a partir da metáfora de cunho conceitual.

Em nossa busca por construções metafóricas de cunho conceitual nas narrativas escritas pelos professores indígenas, encontramos muitas outras construções linguísticas metafóricas, revelando mais, uma vez a riqueza que há em nosso sistema conceitual e principalmente contribuindo para a discussão 
acerca dos aspectos estético-literários em textos de autoria indígena. Como exemplo, podemos tomar as seguintes construções:

(2) Eu tenho certeza que e por causa dessa cor vermelha que chama a atenção dos peixes, porque os peixes quando estão no fundo do rio pensam que e sangue. (A pescaria do povo Kaxarari)

(3) Depois que termina a batição todos saem do lago e volta a beira e espera os peixes ficarem tonto. (Pesca Tradicional)

As construções (2) e (3) nos mostram processos e estados humanos atribuídos ao peixe (pensar; ficar tonto) revelando que o autor/narrador busca elementos que traduzam a sua atitude literária, ou seja, recorre a recursos temáticos, enunciativos e discursivos compartilhados com outros textos ficcionais de natureza literária.

Os exemplos aqui demonstrados revelam o uso, pelos narradores/autores, da conhecida figura da personificação (antropomorfismo), que é uma criação metafórica.

\section{Considerações finais}

A partir dos fundamentos norteadores deste trabalho, consideramos que a análise de construções metafóricas de cunho conceitual é um importante meio para a identificação e compreensão dos processos abstratos em termos concretos presentes nas diferentes culturas. Isto se dá principalmente pela interação dos seres humanos com o meio ambiente.

No que diz respeito ao aspecto cognitivo, vimos o aspecto experiencial da metáfora. Os exemplos analisados neste trabalho nos permitiram formular a conceitualização do corpo humano como um recipiente (contentor) e do ritual como um trajetor, como um objeto físico que se move no espaço. E pudemos propor a construção de esquemas imagéticos pré-conceituais de contentor e de trajetória como base para a construção linguística materializada pelos narradores/autores indígenas.

Por trabalharmos com narrativas escritas, não podemos deixar de reconhecer que a prática escritural indígena é o processo inicial do surgimento da literatura contemporânea indígena; entretanto, já é uma realidade em nosso país. Assim, a análise aqui apresentada, embora ainda bastante preliminar, pretende contribuir para uma reflexão/discussão sobre a metáfora literária a partir do estudo da metáfora de cunho conceitual, além de promover reflexões acerca da literatura contemporânea indígena, pois análises como esta servem de norte para a produção de pesquisas que envolvam narrativas indígenas, bem como trazer o debate sobre o papel do autor/escritor indígena no cenário literário brasileiro. 
Os resultados obtidos são relevantes, pois revelam a importância da concretização da cultura, costumes e crenças, fixadas pela escrita da literatura indígena, tendo os indígenas como os verdadeiros autores de sua história, uma vez que ainda há dificuldade e resistência colonizadora, por parte da sociedade não indígena, para ouvir as vozes dos povos nativos.

\section{Referências}

Almeida, Maria Clotilde. 1999. A arte de ser metáfora: Estudo Interlinguístico Português-Alemão de Índole Cognitiva. Edições Colibri. No 2, pp. 59-74, Lisboa, Portugal.

Araujo, Cassiane Ladeira da Silva. 2014. A alma ameríndia: uma leitura junguiana do mito makunaima. Online: http://www.ufjf.br/darandina/files/ 2010/12/A-almaamer\%C3\%ADndia-uma-leitura-junguiana-do-mito-makunaima1.pdf. Acesso em: $15 / 10 / 2014$

Benjamin, Walter. 1987. Magia e técnica, arte e política. $3^{\mathrm{a}}$ edição. São Paulo, Brasiliense.

Cassirer, Ernest. 1992. Linguagem e Mito. $3^{\mathrm{a}}$ edição. São Paulo: Perspectiva.

Guesse, Érika Bergamasco. 2011. Shenipabu Miyui: literatura escrita indígena como expressão de um legado mítico. 22/07/2011. Online: http://www.abralic.org.br/ anais/cong2011/AnaisOnline/resumos/TC0538-1.pdf

Lakoff, George; Mark Johnson. 2002. Metáforas da vida cotidiana. Campinas, SP: Mercado de Letras, Educ.

Munduruku, Daniel. Literatura indigena e o tênue fio entre escrita e oralidade. Disponível em: http://www.overmundo.com.br/overblog/literatura-indigena. Acesso em: 15/10/2014

Ricoeur, Paul. 2000. A metáfora viva. $2^{\mathrm{a}}$ edição. São Paulo, Loyola.

Souza, Lynn Mario T. Menezes. Que história é essa? A escrita indígena no Brasil. Online: http://pib.socioambiental.org/pt/c/iniciativas-indigenas/ autoria-indigena/ uma-outra-historia,-a-escrita-indigena-no-brasil.

. 2004. Hibridismo e tradução cultural em Bhabha. In: Benjamin Abdala Júnior (Org.). Margens da cultura: mestiçagem, hibridismo e outras misturas. São Paulo: Bomtempo Editorial, pp. 113-133.

Wellek, René; Austin Warren. 1976. Teoria da Literatura. $3^{\text {a }}$ Edição. São Paulo, Europa-América.

Data recebimento: $19 / 04 / 2015$

Data aceite: $15 / 07 / 2015$ 